\title{
The Ethical Imperative to Eradicate Measles
}

Durrheim DN ${ }^{1 *}$ and Dahl-Regis $\mathrm{M}^{2}$

${ }^{1}$ University of Newcastle, Australia and Chair of the Western Pacific Measles Verification Commission, Australia

${ }^{2}$ Chief Medical Officer, Bahamas and Chair of the Pan-American Measles and Rubella Elimination Independent Expert Committee, Australia

*Corresponding author: Durrheim DN, University of Newcastle, Australia and Chair of the Western Pacific Measles Verification Commission, Australia, Tel: 6124921 5000; E-mail: David.Durrheim@hnehealth.nsw.gov.au

Rec date: March 20, 2013, Acc date: April 20, 2013, Pub date: Apr 28, 2013

Copyright: (c) 2014 Durrheim DN, et al. This is an open-access article distributed under the terms of the Creative Commons Attribution License, which permits unrestricted use, distribution, and reproduction in any medium, provided the original author and source are credited.

\section{Introduction}

"There can be no keener revelation of a society's soul than the way in which it treats its children." Nelson Mandela

All governments, health care providers and parents have an obligation to take all reasonable measures to protect today's children, and future generations where possible, against infections that claim their lives or potentially disable them. This is particularly pertinent where a means is available that has been found, across a broad range of settings globally, to be extraordinarily cost-effective [1]. However, despite having a very effective and safe vaccine against measles for the past five decades with two doses providing enduring immunity, infection with measles virus continues to claim approximately 140,000 young lives annually [2]. The virus, which exclusively infects humans in nature, is highly infectious with a basic reproductive rate (i.e. the average number of secondary infections that would result from one person with measles in a fully susceptible population) of between 10 and 20 [3]. The burden of severe disease falls more heavily on children who already have a compromised health status and the risk of infection is greater for marginalized groups of children that have poor access to preventive health services [4].

Although primarily clinically recognized by a benign sounding syndrome of "fever, generalized maculopapular rash, and at least one of coryza, cough or conjunctivitis", measles has exacted a formidable death toll; deaths that could have been prevented if all children were reached with vaccine early in their lives [5]. In 1980 alone there were an estimated 2.6 million deaths due to measles complications [6]. In wealthy countries complications, particularly bronchopneumonia, diarrhoea and otitis media, are common, while acute encephalitis ( 1 in 2000 cases), subacute sclerosing panencephalitis ( 1 in 25000 cases) and death also occur [7]. In developing countries, measles severity is even more devastating [8]. The infection's interplay with poor nutrition and co-infections results in a median community case fatality ratio of about $4 \%$ but reported death rates exceeding $40 \%$ occur in specific settings [9].

\section{Increased Immunization Coverage and Mortality Decline}

Recognizing that low global coverage with measles vaccine had resulted in an unacceptable childhood mortality burden, WHO and UNICEF developed an accelerated measles mortality reduction strategy delivering two doses of measles-containing vaccine to all children through routine services and supplementary immunization activities, and improving disease surveillance [10]. The rapid increase in global measles vaccine coverage had a profound effect on deaths with the global goal of a $50 \%$ reduction in measles deaths by 2005 , when compared with 1999, being achieved [9].
Thus in 2008 the World Health Assembly endorsed a target to reduce measles mortality by $90 \%$ by 2010 when compared with 2000 [6]. Although this goal was not achieved, estimated deaths have dramatically fallen by $74 \%$ from 535,300 in 2000 to 139,300 in 2010 [2]. Indeed reductions in measles mortality accounted for $23 \%$ of the estimated decline in all-cause child mortality from 1990 to 2008 [11] and it is estimated that at least 9.6 million deaths were averted by measles vaccination between 2000 and 2010 [2].

\section{The Feasibility and Need to Eradicate Measles Globally}

In 2010, an expert advisory committee was convened by the World Health Organization to assess the feasibility of measles eradication; the worldwide interruption of measles virus transmission in the presence of a surveillance system that has been verified to be performing well. The panel concluded that eradication was indeed biologically, technically and operationally feasible, as demonstrated in the Region of the Americas and countries in every other Region [12]. The experts concluded that: measles can and should be eradicated; eradication by 2020 was feasible if measurable progress was made toward existing 2015 measles mortality reduction targets; measles eradication activities should occur in the context of strengthening routine immunization services; and measles eradication activities should be used to accelerate control and elimination of rubella and congenital rubella syndrome.

All six WHO regions have established goals to eliminate measles by 2020 and thus a de facto global eradication target date of 2020 is in place. Endemic measles transmission was considered eliminated in the Americas in 2002 and this status has been sustained for over a decade [13]. The Global Vaccine Action Plan stresses the need to meet global and regional vaccine-preventable disease elimination targets [14]. At present, there is a World Health Assembly worldwide goal of a $95 \%$ reduction in measles mortality by 2015 compared with 2000 estimates and progress towards this goal is likely to lead to the World Health Assembly setting a formal eradication target date.

The need to accelerate the global eradication effort is evidenced by an increase in case numbers over the past four years after eight years of declining cases, due to substantial outbreaks in Africa and Europe [15-17]. Reasons for outbreaks primarily relate to the accumulation of susceptible children and young adults due to: inadequate and heterogeneous immunisation coverage due to the failure of health systems to equitably reach all children; ideological opposition resulting in vaccination refusal; and the nature of global travel and migration with myriad opportunities for seeding virus from remaining endemic countries [18].

There has been a concurrent increase of cases in areas in the Eastern Mediterranean where ongoing conflict has disrupted health and other community services. The vast majority of cases unsurprisingly 
occurred in unvaccinated persons, so the main reason for these outbreaks is failure to vaccinate. On reviewing progress towards regional elimination goals in November 2013 the Strategic Advisory Group of Experts on Immunization to the WHO concluded that only two regions (the Americas and Western Pacific) were on track to meet their targets and stressed the importance of achieving greater than $95 \%$ coverage with two doses of measles-containing vaccine uniformly across all countries and districts [19].

\section{The Ethical Imperative to Eradicate Measles}

Despite the positive feasibility assessment and achievement of endemic virus interruption in multiple countries and the Region of the Americas, competing priorities and major financial and programmatic challenges are advanced as reasons for a reversal in progress [20]. Smallpox eradication demonstrated that global political will and strong leadership could overcome obstacles and deliver substantial financial savings. To catalyze political will it is often helpful to explicitly consider and debate the ethical considerations pertinent to aggressively pursuing regional elimination goals to ultimately achieve global measles eradication.

\section{Human Rights and Equity}

The Convention on the Rights of the Child was adopted by the United Nations' General Assembly in November 1989. Article 6 (Survival and development) has direct relevance to the question of feasible disease eradication: "Children have the right to live. Governments should ensure that children survive and develop healthily." Children's rights and social justice demand that all children have equal access to effective childhood immunizations [21].

Considerations of equity are particularly relevant to measles. In 2011 more than 20 million children did not receive their first dose of measles vaccine on time [22]. There is a strong correlation between community wealth and immunization coverage at country level [4]. In addition marginalized groups, including migrants, nomadic communities and the rural poor are more likely to miss out on the benefits of vaccination. As children in these high-risk groups are often at greatest risk of severe disease due to their underlying health status and limited access to health care, reaching them with immunization can have a real impact on health inequalities.

\section{The Duty of Care and Rule to Rescue}

The principle of beneficence dictates that national governments and the international community have a duty of care to ensure that current and future cohorts of children enjoy the protection offered by measles vaccine to prevent them from being placed at risk of severe disease and even death [23]. The strength of the duty of care prerogative depends on the availability of effective and affordable measures, which is satisfied by measles vaccine. The rule of rescue places a compelling obligation on those that are able, in this case governments and health personnel, to "rescue identifiable individuals facing avoidable death" if personal sacrifice is not excessive [23]. It would be hard to argue against implementing innovative and appropriate strategies to reach every last child with measles vaccine to meet this obligation.

Beneficence is influenced by the consequences of doing nothing, the feasibility of preventing serious consequences and the scale of sacrifice. Measles virus is unforgiving in discovering immunity gaps. As coverage declines large-scale outbreaks are inevitable. Economic modeling has demonstrated that a coordinated campaign achieving global interruption of measles virus circulation by 2020 would result in a massive return on investment freeing up considerable finances currently required for treating hospitalized cases and responding to outbreaks [24]. However any decrease in the level of investment will rapidly result in a rebound of cases and deaths with a catastrophic loss of recent gains [11].

\section{Collateral Benefits}

Measles is one of the most contagious vaccine-preventable diseases, and is a sensitive indicator of problems in immunization programmers because of its high communicability and recognizable rash [25]. The surveillance resolution required for rapid detection, confirmation, and response to measles would permit measles outbreaks to accurately identify specific communities missing out on measles vaccine but also other primary health care services. The strengthening of each health system "building block"; service delivery, health workforce, information, vaccine, financing and governance, at local level required to reach at least $95 \%$ of children in every community with potent measles vaccine, would unmistakably bolster the delivery of all other primary child health services $[26,27]$.

\section{"Ubuntu"}

Ubuntu is a Zulu word describing a social and ethical concept, "the essence of being human" [28]. This African philosophy upholds reciprocity as the foundation of being and becoming human. This has particular relevance to the current measles situation with the extraordinary magnitude of international travel implying that while any country continues to harbor endemic measles virus, they place their neighbors and the global community at risk of importation, secondary outbreaks and even re-establishment of transmission if the receiving country has heterogeneous coverage. This has certainly been the experience of the Americas in recent years. Global solidarity demands that all countries exercise good neighborliness and optimize their own coverage to limit the risk they pose. Reciprocity also mandates that better resourced countries will partner with less wellresourced countries to assist them in their quest to achieve the global public good.

\section{Reverence for Life}

Albert Schweitzer, the architect of the reverence for life principle summarized it as: "Ethics are responsibility without limit toward all that lives" [29]. He contended that every life is precious. Failing to complete the task of eradicating measles, would be an unacceptable act of omission by the global community. Every death of a child due to measles after 2020 would be an indictment on our shared humanity.

\section{Conclusion}

The global community, each country government and every health worker is ethical bound to reinvigorate measles elimination efforts and do everything possible to ensure that proven strategies are robustly and universally implemented. In endorsing the Global Vaccine Action Plan in May 2012, the 194 member states of the World Health Assembly explicitly acknowledged that to achieve measles eradication, equitable high vaccination coverage would be required in every community, including those that currently have poorer access to preventive health services [30]. An uncompromising global effort 
against measles could be an effective catalyst to ensuring effective reach of other child health programmers to all children who need them most.

Measles eradication should not remain just a technically feasible possibility but rather be completed to ensure that future generations of children do not live under the shadow of preventable childhood measles deaths.

\section{References}

1. World Health Organization (2012) Global measles and rubella strategic plan, 2012-2020. Geneva: World Health Organization. Available at: http://www.measlesrubellainitiative.org/wp-content/uploads/2013/06/ Measles-Rubella-Strategic-Plan.pdf.

2. Simons E1, Ferrari M, Fricks J, Wannemuehler K, Anand A, et al. (2012) Assessment of the 2010 global measles mortality reduction goal: results from a model of surveillance data. Lancet 379: 2173-2178.

3. Anderson RM, May RM (1992) Infectious diseases of humans. Dynamics and control. Oxford: Oxford University Press: 70.

4. Hinman AR (2004) Immunization, equity, and human rights. Am J Prev Med 26: 84-88.

5. Orenstein WA1, Hinman AR (2012) Measles: the burden of preventable deaths. Lancet 379: 2130-2131.

6. Strebel PM1, Cochi SL, Hoekstra E, Rota PA, Featherstone D, et al. (2011) A world without measles. J Infect Dis 204 Suppl 1: S1-3.

7. Orenstein WA1, Papania MJ, Wharton ME (2004) Measles elimination in the United States. J Infect Dis 189 Suppl 1: S1-3.

8. Moss WJ1, Griffin DE (2012) Measles. Lancet 379: 153-164.

9. Wolfson LJ1, Strebel PM, Gacic-Dobo M, Hoekstra EJ, McFarland JW, et al. (2007) Has the 2005 measles mortality reduction goal been achieved? A natural history modelling study. Lancet 369: 191-200.

10. World Health Organization (2012) Progress in global measles control, 2000-2010. Wkly Epidemiol Rec 87: 45-52.

11. van den Ent MM1, Brown DW, Hoekstra EJ, Christie A, Cochi SL (2011) Measles mortality reduction contributes substantially to reduction of all cause mortality among children less than five years of age, 1990-2008. J Infect Dis 204 Suppl 1: S18-23.

12. Durrheim DN, Bashour H (2011) Measles eradication. Lancet 377: 808.

13. World Health Organization (2009) Global elimination of measles: report by the Secretariat. Executive Board 125th Session, 16 April 2009 (EB125/4). Available at: http://apps.who.int/gb/ebwha/pdf_files/EB125/ B125_4-en.pdf (Cited 8 March 2014).

14. Decade of Vaccines Collaboration (2013) Global Vaccine Action Plan. Vaccine 31: S5-S31.

15. [No authors listed] (2011) Measles outbreaks and progress towards meeting measles pre-elimination goals: WHO African Region,2009â €“2010. Wkly Epidemiol Rec 86: 129-136.
16. Centers for Disease Control and Prevention (CDC) (2012) Progress in global measles control, 2000-2010. MMWR Morb Mortal Wkly Rep 61: 73-78.

17. European Centre for Disease Prevention and Control (2012) European monthly measles monitoring. Issue 8: 21 February 2012. Available at: http://ecdc.europa.eu/en/publications/Publications/

SUR_EMMO_European-monthly-measles-monitoring-

February-2012.pdf

18. Kuehn BM (2014) Public health officials mark 50th year of measles vaccine: concern remains about outbreaks in pockets of unvaccinated. JAMA 311: 345-346.

19. [No authors listed] (2014) Meeting of the Strategic Advisory Group of Experts on immunization, November 2013 -- conclusions and recommendations. Wkly Epidemiol Rec 89: 1-20.

20. World Health Organization (2011) Proceedings of the Global Technical Consultation to assess the feasibility of measles eradication, 28-30 July 2010. J Infect Dis 204 Suppl 1: S4-13.

21. Duclos P1, Okwo-Bele JM, Gacic-Dobo M, Cherian T (2009) Global immunization: status, progress, challenges and future. BMC Int Health Hum Rights 9 Suppl 1: S2.

22. World Health Organization (2013) Progress in global control and regional elimination of measles, 2000-2011. Wkly Epidemiol Rec 88: 29-36.

23. Murphy L (2001) Beneficence. Georgetown Law J 3: 605-665.

24. Levin A, Burgess C, Garrison LP Jr, Bauch C, Babigumira J, Simons E, Dabbagh A (2011) Global eradication of measles: an epidemiologic and economic evaluation. J Infect Dis 204: S98-S106.

25. Orenstein WA (2006) The role of measles elimination in development of a national immunization program. Pediatr Infect Dis J 25: 1093-1101.

26. Fields R1, Dabbagh A, Jain M, Sagar KS (2013) Moving forward with strengthening routine immunization delivery as part of measles and rubella elimination activities. Vaccine 31 Suppl 2: B115-121.

27. Hinman AR (2011) Integration of eradication initiatives and health systems. In: Cochi SL, Dowdle WR, editors. Disease eradication in the 21st century: Implications for global health. Strungmann Forum Report volume 7. Cambridge: MIT Press.

28. Tutu DM (1999) No future without forgiveness. New York: Double Day publishing.

29. Schweitzer A (1987) The philosophy of civilization. New York: Prometheus Books, 1987.

30. World Health Organization (2013) Global Vaccine Action Plan, 2011-2020. Geneva: World Health Organization. Available at: http:// www.who.int/immunization/global_vaccine_action_plan/en/ 